\title{
midiäticaje
}

\section{A representação do feminino na tela: uma análise da cinematografia brasileira postulante ao Oscar de melhor filme em língua estrangeira (2010 - 2016)}

\author{
The female representation on screen: an analysis of the Brazilian cinematography \\ postulant to the Oscar of best foreign language film (2010 - 2016)
}

Jéssica FRAZÃO ${ }^{1}$

\begin{abstract}
Resumo
O cinema feminista manifesta-se em um momento voltado para criação de uma linguagem cinematográfica destinada a coibir a visão sexista existente em relação à mulher representada na tela, iniciada ainda na construção narrativa, aceita e reafirmada de igual maneira pelo espectador. Este artigo reúne algumas reflexões teóricas e analisa a construção da personagem feminina nos filmes brasileiros indicados para concorrer ao Oscar, utilizando como aporte teórico os estudos elaborados pelas teorias feministas do cinema. Metodologicamente, utiliza-se o Teste de Bechdel, ferramenta consoante com as discussões, para analisar um período de seis anos de filmes brasileiros candidatos à categoria de melhor filme em língua estrangeira (2010 a 2016). Os resultados apontam para algum avanço, mas ainda assim demonstram a necessidade de criação de narrativas menos simplórias em relação ao papel da personagem.
\end{abstract}

Palavras-chave: Cinema feminista. Cinema brasileiro. Filme estrangeiro. Teste de Bechdel.

\begin{abstract}
Feminist cinema came into the light together with the cinematographic language destined to restrain sexist vision related to how woman was represented on the screen, an approach which begins in the narrative construction and is accepted and reaffirmed by the spectator. Using as a theoretical contribution the studies elaborated by feminist cinema theories, this article tries to comprehend the construction of the female character in the Brazilian films nominated to compete for the Oscars. Methodologically, the Bechdel Test is applied for analysing a six-year period of Brazilian films candidates for best foreign language film (2010 to 2016). The results point to some progress, but still, suggests the need for less simplistic narratives in relation to the character's role.
\end{abstract}

Keywords: Feminist cinema. Brazilian cinema. Foreign film. Bechdel test.

\footnotetext{
${ }^{1}$ Mestre pelo Programa de Pós-Graduação em Comunicação (PPGCOM/UFPR).

E-mail: jessicafrazao@hotmail.com
} 


\section{midiätica@e}

\section{Introdução}

O cinema, ainda hoje, tem sido uma arte predominantemente masculina. Indicações sobre feminino e masculino, pelo reforço da diferença, são constantemente afirmadas neste espaço. Houve para os organizadores do maior prêmio do cinema comercial, oficialmente chamado de prêmios da Academia e popularmente conhecido como Oscar, um aumento de interesse nas últimas décadas em discutir como são representadas as questões de gênero em âmbito cinematográfico. Não apenas, este corpo artístico buscou ampliar a leitura dos filmes recebidos atentando-se para tais aspectos, não se bastando apenas no sentido prático e artístico da produção cinematográfica, mas também com contribuições da esfera acadêmica.

As teorias feministas do cinema são responsáveis por abrir o debate acerca da noção de autoria, ponto de vista, relações dentro do set, tipo de espectador, e reconfiguram a posição da mulher representada outrora no cinema narrativo clássico unicamente pela sua sensualidade, feminilidade e forte ligação com desejo masculino, como menciona Laura Mulvey em "Prazer Visual e Cinema Narrativo". A cinematografia brasileira por vezes está em conformidade com tais aspectos.

O Ministério da Cultura, por sua vez, indica uma quantidade significativa de filmes à cerimônia do Oscar, promovida anualmente pela Academia de Artes e Ciências Cinematográficas de Hollywood (Academy of Motion Picture Arts and Sciences), apesar da disparidade se comparado com países como Itália e França.

A possibilidade de ganhar uma estatueta do Oscar, o prêmio do cinema de maior status e impacto, influencia fortemente os países no que diz respeito à escolha do filme que será indicado para concorrer na categoria de Melhor Filme em Língua Estrangeira. Para a indicação, a obra cinematográfica deve conter elementos intrínsecos de 'brasilidade", e ao mesmo tempo possuir um caráter e linguagem internacional, a fim de facilitar a compreensão de sua narrativa além das fronteiras.

Pretendendo questionamentos que tencionem as abordagens feministas do cinema no que tange à representatividade feminina nas telas, o prêmio da Academia e as indicações envolvidas pensando a visibilidade desta premiação e cerimônia, esta proposta analisará os seguintes filmes: Salve Geral (concorreu em 2010), Lula: O filho do Brasil (concorreu em 2011), Tropa de Elite 2: O inimigo agora é outro (concorreu 


\section{midiäticale}

em 2012), O Palhaço (concorreu em 2013), O Som ao Redor (concorreu em 2014), Hoje eu quero voltar sozinho (concorreu em 2015) e Que horas ela volta? (concorreu em 2016).

Procura-se conhecer elementos comuns a todos eles no que diz respeito à construção da imagem da mulher dentro da narrativa, permitindo uma compreensão mais aprofundada e criteriosa da visão que o cinema brasileiro faz acerca do feminino. Mais especificadamente, detecta-se características físicas e emocionais da personagem feminina à luz dos papeis de gênero expostos na narrativa. Por meio da comparação das obras e da observação detalhada, identifica-se se os filmes escolhidos passariam ou não no Teste de Bechdel, explicado mais à frente.

\section{A categoria de melhor filme em língua estrangeira}

A categoria de Melhor Filme em Língua Estrangeira (Best Foreign Language Film) existe desde 1956, com o propósito de valorizar a produção cinematográfica de outros países. Apontando seus parâmetros, ela deve ser vista a partir do regimento, que reforça primeiramente aspectos quanto à elegibilidade: Necessariamente, a obra precisa ser um longa-metragem produzido fora dos Estados Unidos, e que tenha predominantemente diálogos em outro idioma que não em língua inglesa. Após, deve ser analisada quanto à submissão, o que representa que o país, convidado pela Academia, terá apenas um filme aceito no processo. Isso confirma a alegação de que muitos países sequer chegarão a concorrer na categoria (BONA; FRAZÃO, 2015).

Desse modo, a seleção dos filmes que chega até Hollywood é feita por um conselho, no qual fazem parte profissionais do campo do audiovisual. Esta seleção inicial é individual e secreta, e posteriormente faz-se uma votação para chegar no resultado dos cinco melhores. Por fim, decide-se por um vencedor, após reverem todos os filmes mais votados. Tornar público os filmes finalistas não são permitidos até que os organizadores do evento permitam. (ACADEMY OF MOTION PICTURE ARTS AND SCIENCES, 2018, online).

O número de filmes participantes na categoria tem, anualmente, um aumento significativo. Este aumento dificulta o processo porque exige do comitê de seleção tempo hábil para assistir aos filmes. É desta forma que o comitê "normalmente acaba 


\section{midiäticales}

sendo composto por profissionais que estejam afastados há algum tempo da atividade, aposentados ou inativos; normalmente mais sensíveis e resistentes a filmes com estéticas ou temáticas mais ousadas" (HAURELHUK, 2008, p.79).

Além disso, outros fatores podem ser considerados, como a complexa e confusa escolha dos filmes finalistas na categoria de Melhor Filme em Língua Estrangeira. A decisão é feita, muitas vezes, por uma comissão estadunidense, com valores culturais e visões de mundo próprias. Em outras palavras, a obra precisaria ter, apesar de pertencente à cinematografia nacional, um caráter universal, além de ser um sucesso de crítica e bilheteria. Por este ângulo, o fato de o Brasil nunca ter figurado entre os finalistas na categoria ocorre possivelmente pelo uso de regionalismos, religiosidade e condições culturais características, algo que não ultrapassa as fronteiras nacionais.

\section{As teorias feministas do cinema}

Segundo Joan Scott (1989), as tentativas de compreensão do conceito "gênero" são mais complicadas do que se imagina, visto que se tende a generalizar, simplificar ou diminuir a complexidade que este exige. Os estudos feministas surgiram como uma maneira de refletir e analisar mais concretamente as mudanças que deveriam ser feitas no que diz respeito às relações de poder e a forma de se pensar as mulheres na sociedade.

A questão das identidades de gênero passa, então, a ser uma realidade no cinema a partir de maio de 1968, quando a base sustentadora das teorias cinematográficas se torna a psicanálise, a semiótica e o marxismo, especificadamente com os estudos de Lacan, Saussure e Althusser. O questionamento advindo das representações femininas reforçadas pelo cinema narrativo clássico ${ }^{2}$ foi o primeiro passo para a concepção de uma teoria feminista cinematográfica.

Laura Mulvey (1983), teórica do cinema e feminista, tendo à psicanálise como referência, descreveu em seu clássico ensaio: "Prazer Visual e Cinema Narrativo", como ocorre a relação entre cinema narrativo tradicional (enraizado nos pensamentos

\footnotetext{
${ }^{2} \mathrm{O}$ cinema narrativo clássico, também conhecido como a Era de Ouro de Hollywood, consolida-se a partir de 1914 e tem como princípio básico às narrativas simples feitas para a massa e a montagem invisível (na qual o espectador não identifica montagem alguma), aumentando assim, a noção de realidade (XAVIER, 1977).
} 


\section{midiäticale}

patriarcalistas), prazer visual e a escopofilia ${ }^{3}$. Mulvey propôs uma ruptura dessa perspectiva, tipicamente masculina, através de uma nova forma de desejo, partindo para um contra cinema. Tal análise serviu como fortalecimento para a expansão da teoria e crítica feminista do cinema (MALUF, MELLO e PEDRO, 2005).

O prazer visual ao qual se refere Mulvey é basicamente a ideia de um "olhar masculino" que reforça a opressão em relação à mulher representada na tela e fortalece uma visão sexista tanto em relação ao público/espectador, quanto em relação ao próprio ponto de vista dos personagens representados narrativamente. Para isto, a mulher tende a possuir relevância menor em relação ao homem. A personagem feminina possui, segundo a autora, dois papeis nestas narrativas clássicas: de objeto erótico para o personagem masculino e de objeto erótico para a audiência.

A mulher, desta forma, existe na cultura patriarcal como o significante do outro masculino, presa por uma ordem simbólica na qual o homem pode exprimir suas fantasias e obsessões através do comando lingüístico, impondo-as sobre a imagem silenciosa da mulher, ainda presa a seu lugar como portadora de significado e não produtora de significado (MULVEY, 1983, p.438).

Mulvey, que também é diretora, ao lado de Sally Potter, perceberam a urgência em criar uma nova linguagem do cinema, uma linguagem feminista. O cinema avantgarde era meio propicio para quebras de paradigmas e construção de ideias mais igualitários. Justamente pela sua proposta mais experimental, foi muito difícil alcançar uma audiência, já que o público em geral pouco compreendia a proposta das cineastas. Entretanto, algumas críticas a esta asserção apontam que faria mais sentido, naquele momento, utilizar convenções cinematográficas reconhecíveis ao grande público para explicar a problemática envolvendo o cinema comercial, ao invés de uma linguagem mais complexa, experimental ou desenvolvida.

No final dos anos 1970, as perspectivas feministas do cinema já eram familiarizadas por escritoras e acadêmicas, que viam nestas uma resposta positiva de mudança no mundo. Entretanto, nem todas as feministas identificavam-se com a vertente psicoanalítica proposta por Mulvey com base em Freud e Lacan, já que tendia a focar mais no individual e pouco no coletivo. Desta forma, as feministas reformularam e

\footnotetext{
${ }^{3}$ Prazer advindo do olhar ou observação de órgãos ou atos sexuais. 


\section{midiäticales}

propuseram outras vertentes que, sem ignorar a importância dos estudos mulveyanos, ampliaram a discussão do campo, a exemplo de debates mais voltados para o cinema lésbico e negro.

Em oposição ao pensamento de Mulvey, a perspectiva de Teresa de Lauretis (1987) consiste em apontar algumas fraquezas das teorias feministas, considerando uma não generalização da mulher e do homem. A autora ressalta a necessidade de demarcar as diferenças tanto em relação às personagens quanto em relação às espectadoras, uma vez que existem variantes na constituição das identidades de gênero e no discurso. Em resumo, há uma tentativa de desvinculação do sexo biológico de quem assiste.

Uma terceira autora, referência nos estudos de gênero no cinema, é a norteamericana Elizabeth Ann Kaplan, também conhecida como uma das pioneiras nos estudos do "olhar masculino" sobre o cinema narrativo clássico predominante nos anos de 1940 e 1950. A autora reforça o papel dos filmes independentes dos anos de 1970 e 1980 como fundamentais para repensar a questão da sexualidade e do gênero em si.

Em uma de suas contribuições mais importantes, Is the Male Gaze? (O olhar é masculino?), entende-se mais profundamente a relação da psicanálise e das especificidades das diferenças sexuais, bem como a dificuldade de ruptura do sistema patriarcal com a luta por igualdade de gênero (KAPLAN, 2002). É dentro deste contexto que foi criado o teste de Bechdel, comentado a seguir. Não é intenção desta proposta intentar que uma perspectiva se sobressaia à outra, e sim, a partir da comparação das autoras, reforçar o diálogo com o campo do cinema e das teorias feministas.

\section{O teste de Bechdel}

O Teste de Bechdel surgiu em 1985, se popularizou e recebeu esse nome a partir de uma história em quadrinhos conhecida como Lésbicas para se ficar de olho (Dykes to Watch Out For) e mais especificadamente, em uma tirinha chamada A regra (The Rule), feita pela cartunista Alison Bechdel. Ela criou uma personagem (baseada em sua amiga Liz Wallace) que só assistia a filmes se estes passassem em três simples regras que hoje compõem o Teste de Bechdel: Existem pelo menos duas personagens femininas? (1); existe um diálogo entre elas? (2); as personagens conversam sobre algo que não um homem? (3). 


\section{midiática@e}

O teste é utilizado em filmes, séries, entre outros produtos audiovisuais para avaliar o sexismo e a desigualdade de gênero existente no cinema (BECHDELTEST, 2018, Online). O Teste, aparentemente simples, mostrou que uma porcentagem considerável de filmes não obtém resultado positivo.

A proposta do teste, apesar disto, é mais controversa do que se acredita. Basearse em três perguntas para avaliar se um filme é sexista ou não é uma forma simplista de julgamento. Muitas obras cinematográficas não passariam no teste e ainda assim, não deveriam ser vistas como sexistas. Exemplo disso é o filme alemão Corra Lola, Corra (Lola Rennt, 1998), dirigido por Tom Tykwer, que conta a história da personagem Lola, desesperada para conseguir cem mil marcos em dinheiro e evitar que seu namorado seja assassinado.

O filme é contado de forma não linear e mostra três perspectivas possíveis para o desenvolvimento e conclusão da narrativa. Lola em nenhum momento se depara com outra mulher e tem um diálogo com ela. Nem por isso ela deixa de ser uma personagem extremamente forte e complexa, dona de sua própria vida e que não espera sentada que as coisas lhe aconteçam. Ainda que a intenção de Lola seja salvar seu namorado, a personalidade da personagem a faria fazer qualquer coisa do seu interesse.

Além de Corra Lola, Corra, outros filmes são possíveis de serem listados, o que mostra que o Teste de Bechdel não deve ser visto como única possibilidade de análise, mas ainda assim é um enorme divisor de águas, denunciativo de narrativas simplórias. Um outro exemplo são análises de filmes com caráter histórico, bastante prejudicados em tal forma de observação. A maior crítica ao Teste está em julgar, aos os olhos de hoje, mulheres que são representadas de acordo com valores culturais de uma determinada época. A personagem feminina pode ser "a dona da história", e fora desses critérios ainda ser bem construída. O teste não deve ser visto como verdade única, mas em se tratando do público feminino como sendo metade da população do planeta, é urgente que o cinema represente as mulheres de forma, no mínimo, menos sexista (HARRIZ, 2010).

No Brasil, o sistema patriarcal enormemente influencia os filmes, inclusive no que diz respeito àqueles enviados, ano após ano, para a Academia de Hollywood, com o propósito de serem indicados à categoria de Melhor Filme Estrangeiro. Observa-se que apenas pouco mais da metade dos filmes enviados nos últimos anos passaram nas três 


\section{midiäticales}

perguntas do Teste de Bechdel. Ainda que o teste não sirva como único parâmetro de definidor de igualdade, a partir dele foi possível refletir a respeito da representação da mulher no cinema nacional. A mulher ainda está em menor número também por trás das câmeras, ainda faz papéis pouco complexos, ainda é representada de modo a ressaltar sua feminilidade, sensualidade e em favor da fantasia masculina.

A preocupação em torno das questões de gênero a longo e médio prazo, com efeito, não foi significativa para a Academia. Mark Harris (2010) disse uma vez à revista Entertaiment Weekly: "Se o Teste de Bechdel tivesse sido de repente implantado em Hollywood com as forças da lei, ele teria seriamente prejudicado cinco dos dez filmes indicados a Melhor Filme no ano passado"4 (tradução livre). Reforçando o caráter sexista dos filmes Hollywoodianos, a atriz norte-americana Claire Danes, em entrevista à revista Vogue Magazine, comentou sobre a possibilidade de desistir da carreira de atriz por alguns anos, em razão de quase sempre oferecerem a ela papéis estereotipados de uma simples garota dependente, sem muito além disso. (MCGUINNESS, 2013).

Por esta ótica, A New York Film Academy realizou, em 2013, uma pesquisa sobre mulheres no cinema, tendo como análise os quinhentos filmes mais vistos em um período de 2007 e 2012. O resultado mostra que a igualdade de gêneros no cinema está longe de ser um ideal. Somado a isto, os membros ativos e votantes da Academia de Ciências Cinematográficas de Hollywood eram, em 2014, em sua grande maioria homens brancos (94\%), com média de idade de 63 anos.

Pensando alternativas para a falta de representatividade dos seus membros em anos anteriores, a Academia admitiu em 2016 novos 283 nomes, pertencentes a cinquenta e três países. Entre estes estão os brasileiros Anna Muylaert, diretora do aclamado Que Horas Ela Volta, e Alê Abreu, diretor e animador de O Menino e o Mundo. Recentemente, portanto, dado o aumento das críticas, percebeu-se algumas mudanças positivas da Academia no sentido de ampliar à diversidade de gênero e étnico-racial.

\footnotetext{
${ }^{4}$ Do original: If the Bechdel Test had suddenly landed in Hollywood with the force of law, it would have seriously jeopardized five of last year's 10 Best Picture nominees.
} 


\section{midiätica@e}

\section{Procedimentos metodológicos e resultados de análise}

Para a construção do quadro de análise foram observados: fatores gerais do filme, como o gênero cinematográfico e sua época, bem como fatores pontuais sobre a construção da personagem feminina. Por fim, observa-se se o filme passaria (mesmo que por uma cena), no teste de Bechdel. Elaborou-se um quadro referente ao ano da cerimônia do Oscar em que a obra foi indicada a concorrer na categoria de filme estrangeiro e nome do diretor. A pesquisa sobre a filmografia dos vencedores na categoria de Melhor Filme em Língua Estrangeira foi realizada a partir das informações publicadas na página de internet IMDb (Internet Movie Database, 2018, online), representando, portanto, o corpus da investigação. A escolha do corpus justifica-se pela relação de acesso obra e espectador, e pela importância dos prêmios da Academia no universo cinematográfico, já mencionado. Na sequência, tem-se a tabela utilizada como referência para a análise das obras e da personagem feminina:

Tabela 1 - Filmografia analisada

\begin{tabular}{ccc}
\hline Ano (Cerimônia do Oscar) & Filme & Diretor \\
\hline 2010 & Salve Geral & Sérgio Rezende \\
2011 & Lula: O filho do Brasil & Fábio Barreto \\
2012 & Tropa de Elite 2: O inimigo & José Padilha \\
2013 & agora é outro & S Palhaço \\
2014 & O som ao redor & Kleber Mendonça Filho \\
2015 & Hoje eu quero voltar sozinho & Daniel Ribeiro \\
2016 & Que horas ela volta? & Anna Muylaert \\
\hline
\end{tabular}

Fonte: IMDb (2018)

Os resultados a seguir foram coletados por meio da análise dos seis filmes brasileiros postulantes ao Oscar de Melhor Filme em Língua Estrangeira, indicados na tabela 1. As obras foram assistidas cada uma por duas vezes durante a realização do estudo e a observação se deu de acordo com os apontamentos da tabela 2. 


\section{midiätica@e}

Tabela 2 - Análise dos aspectos gerais do filme

\begin{tabular}{ccc}
\hline & $\begin{array}{c}\text { ASPECTOS GERAIS DO } \\
\text { FILME }\end{array}$ & \\
\hline GÊNERO DO & QUANTIDADE DE & PORCENTAGEM \\
FILME & FILMES & $100 \%$ \\
Drama & 7 & $28 \%$ \\
Ação & 2 & $14 \%$ \\
Romance & 1 & $14 \%$ \\
Suspense & 1 & $14 \%$ \\
Comédia & 1 & $0 \%$ \\
Ficção Científica & 0 & PORCENTAGEM \\
HISTórIA & QUANTIDADE DE & $14 \%$ \\
De época & FILMES & $85 \%$ \\
\hline Contemporânea & 6 & \\
\hline
\end{tabular}

Fonte: A autora (2018)

Os resultados demonstram que todos os filmes indicados a concorrer na categoria de Melhor Filme em Língua Estrangeira, no período indicado, foram do gênero Drama (100\%). É importante ressaltar que não necessariamente a filmografia analisada encaixou-se apenas em um gênero, podendo ser categorizada em até dois deles. Ainda assim, como o gênero Drama esteve presente em 100\% dos filmes, mostrase a preferência do estilo nas indicações brasileiras. Ainda neste sentido, seis dos sete filmes analisados são contemporâneos, com exceção de Lula: O filho do Brasil, pelo teor histórico geralmente presente em cinebiografias.

Tabela 3 - Análise das características da personagem feminina

\begin{tabular}{ccc}
\hline & CARACTERÍSTICAS DA & \\
& PERSONAGEM FEMININA & \\
\hline PAPEL NO FILME & QUANTIDADE DE & PORCENTAGEM \\
Protagonista & FILMES & $42 \%$ \\
Coadjuvante & 3 & $56 \%$ \\
CARACTERÍSTICAS & 4 & PURCENTAGEM \\
PSICOLÓGICAS & FILMES & $70 \%$ \\
Autônoma e independente & 5 & $56 \%$ \\
Submissa e dependente & 4 & PORCENTAGEM \\
CARACTERÍSTICAS & QUANTIDADE DE & $56 \%$ \\
FÍSICAS & FILMES & $14 \%$ \\
Com idade de até 30 anos & 4 & 1 \\
De 31-40 anos & &
\end{tabular}




\section{midiäticale \\ REVISTA DO PROGRAMADE \\ PÓS-GRADUAÇÃO EM COMUNICAÇÃO DA \\ UNIVERSIDADE FEDERAL DA PARAIBA}

\begin{tabular}{|c|c|c|}
\hline De $41-50$ anos & 1 & $0 \%$ \\
\hline Acima de 50 anos & 0 & $0 \%$ \\
\hline Vários períodos da vida & 1 & $14 \%$ \\
\hline Pele clara & 3 & $42 \%$ \\
\hline Pele morena & 4 & $56 \%$ \\
\hline
\end{tabular}

Fonte: A autora (2018)

A principal observação a ser ressaltada a partir da leitura da tabela é o fato das atrizes ainda estarem em mais papéis coadjuvantes do que protagonistas, apesar da diferença pequena. Em relação à personagem feminina, trata-se de uma mulher autônoma e independente (70\%), com idade de até 30 anos (56\%), e pele morena (ambos 56\%). A personagem que faz a mãe de Luiz Inácio no filme Lula: O filho do Brasil mostrou uma mudança clara de personalidade, indo de dependente a independente, assim como a personagem Val em Que horas ela volta?. Isso se deu graças ao crescimento da própria personagem na estrutura narrativa.

Tabela 4 - Análise Teste de Bechdel

\begin{tabular}{lcc}
\hline \multicolumn{1}{c}{ QUESTÕES } & $\begin{array}{c}\text { TESTE DE } \\
\text { BECHDEL }\end{array}$ & \\
\hline \multicolumn{1}{c}{$\begin{array}{c}\text { QUANTIDADE DE } \\
\text { FILMES }\end{array}$} & $\mathbf{1 0 0 \%}$ \\
$\begin{array}{l}\text { Existem pelo menos } \\
\text { duas personagens } \\
\text { femininas com } \\
\text { nomes? }\end{array}$ & $\mathbf{7}$ & \\
$\begin{array}{l}\text { Existe um diálogo } \\
\text { entre elas? }\end{array}$ & 4 & $\mathbf{5 6 \%}$ \\
$\begin{array}{l}\text { Sobre algo que não } \\
\text { um homem? }\end{array}$ & $\mathbf{4}$ & $\mathbf{5 6 \%}$ \\
\hline
\end{tabular}

Fonte: A autora (2018)

Na tabela 4, ressalta-se que $100 \%$ dos filmes atendem a primeira pergunta do Teste de Bechdel. Porém, as investigações deixaram claro que este critério não se faz difícil de transparecer, em se tratando de um filme de longa-metragem. Em relação às duas outras perguntas, esse número cai para pouco mais da metade (56\%). Considerando diálogos em qualquer circunstância ou ocasião e com qualquer duração de tempo, algumas obras passaram no teste apenas por conter cenas dialógicas esporádicas no decorrer da narrativa.

Tendo o cinema enquanto um valoroso dispositivo de representação de um constructo social, mulheres nas narrativas cinematográficas ainda estão envoltas de 


\section{midiäticale}

estereótipos e são condicionadas por disputas por homens e necessidade de ser feminina e sensual, como outrora falava Mulvey. Como mencionado, apesar das falhas do teste e impossibilidade de ser o único marcador, ainda assim tem-se uma leitura de viés audiovisual para uma criação social e cultural de gênero.

\section{Conclusão}

Após maio de 1968, novos estudos surgiram no campo do feminismo, refletindo no progresso dos movimentos culturais e, consequentemente, no cinema. As teorias feministas cinematográficas buscaram diagnosticar, primeiramente, a representação da mulher de acordo com uma visão tipicamente masculina, pensada com uma fórmula sexista desde o início do cinema narrativo clássico. Na época referenciada, a mulher era tida como objeto erótico, e via-se principalmente na escopofilia uma forma de prazer.

No que tange à representação da mulher nos filmes com ativa participação destas teorias como contraponto, podemos concluir que a Academia de Hollywood compactuou durante muitas décadas com tal perspectiva, preocupando-se pouco com a adaptação dos filmes ao Teste de Bechdel ou visando à eliminação total do sexismo. As estatuetas entregues na noite do Oscar, apesar de muitas melhorias, ainda estão longe do ideal em atuar com estratégia a adequar-se às teorias feministas do cinema, propostas ainda na década de 1970, para buscar mais igualdade nas representações. Além da questão da personagem na estrutura narrativa, o número de mulheres diretoras, diretoras de fotografia, produtoras, roteiristas e outras profissionais continua bastante desigual.

No Brasil, o sistema patriarcal enormemente influencia os filmes, inclusive no que diz respeito àqueles enviados, ano após ano, para a Academia de Hollywood, com o propósito de serem indicados à categoria de Melhor Filme Estrangeiro. Observou-se que apenas pouco mais da metade dos filmes analisados passaram nas três perguntas do Teste de Bechdel. Ainda que o teste não sirva como único parâmetro de definidor de igualdade, a partir dele foi possível refletir a respeito da representação da mulher no cinema nacional. A mulher ainda está em menor número por trás das câmeras, ainda faz papéis pouco complexos, ainda é representada de maneira a ressaltar sua feminilidade, sensualidade e em favor da fantasia masculina.

Ainda assim, transformações vieram a partir de 2016, quando a Academia 


\section{midiäticales}

amplamente atentou-se para a desaprovação da audiência em relação ao seu corpo atuante e convidou pessoas de outros países para integrá-lo, entre estes novos nomes, a diretora brasileira Anna Muylaert. A primeira vez em que tivemos uma diretora reconhecida na lista dos representantes a concorrer ao Oscar foi em 1986, ano em que Suzana Amaral dirigiu o longa A hora da estrela. A segunda mulher a figurar nesta lista foi justamente Anna Muylaert, em 2016, com o longa Que horas ela volta?. Estas modificações representam um avanço positivo, reflexo de desdobramentos contemporâneos em que o cinema pode ser visto como ferramenta para análise social e histórica.

\section{Referências}

ACADEMY OF MOTION PICTURE ARTS AND SCIENCES. Special rules for the best foreign language film award. Disponível em: <http://www.oscars.org/sites/oscars/files/91aa_rules.pdf>. Acesso em: 14 de julho 2018.

BECHDEL TEST. Bechdel test. Disponível em: < http://bechdeltest.com/>. Acessado em: 02 de julho 2018.

BONA, Rafael; FRAZÃO, Jéssica. O estrangeiro para a academia de artes e ciências cinematográficas de Hollywood: os vencedores do Oscar de melhor filme em língua estrangeira (2005 $\quad-\quad$ 2014). Linguagens. Revista de Letras, Artes e Comunicação. Blumenau, Vol. 9, No. 2, p. 122-135, mai./ago. 2015.

HARRIS, Mark. I am woman. Hear me... Please!. Entertaiment Weekly. Disponível em < https://ew.com/article/2010/08/06/i-am-woman-hear-me-please/>. Acesso em: 20 de março 2018.

HAURELHUK, Felipe Sembalista. O Oscar foi para... Entendendo o maior prêmio cinematográfico mundial e sua relação com a cinematografia brasileira. 161p. Monografia (Curso de Comunicação social com habilitação em Cinema) - Universidade Federal Fluminense, Niterói, 2008. Disponível em: < file:///C:/Users/Windows/Downloads/5-17-1-PB.pdf>. Acesso em: 09 de julho 2018.

IMDB. IMBd. Disponível em: < https://www.imdb.com/>. Acesso em: 14 de março 2018.

KAPLAN, Ann. A mulher no cinema segundo Ann Kaplan - entrevista a Denise Lopes. Revista Contracampo, Vol. 7, No. 0, p. 209-216, 2002.

DE LAURETIS, Teresa. Technologies of gender: essays on theory, film and fiction. Bloomington: Indiana University Press, 1987. 


\section{midialticale}

MALUF, Sônia Weidner; MELLO, Cecilia Antakly de; PEDRO, Vanessa. Políticas do olhar: feminismo e cinema em Laura Mulvey. Revista de Estudos feministas, Vol. 13, No. 2, p. 343-350, mai./ago. 2005.

MCGUINNESS, Ross. The Bechdel test and why Hollywood is a man's, man's, man's world. Metro UK. Disponível em: <https://metro.co.uk/2013/07/18/movielovers-hit-back-at-hollywood-misogyny-with-the-bechdel-test-3886103/>. Acesso: 20 de março 2018.

MULVEY, Laura. Prazer visual e o cinema narrativo. In: XAVIER, Ismail (Org.). A experiência do cinema. Rio de Janeiro, Graal, 1983.

SCOTT, Joan. Gender: a useful category of historical analyses. In: Gender and the politics of history. New York, Columbia University Press, 1989.

XAVIER, Ismail. O discurso cinematográfico: a opacidade e a transparência. Rio de Janeiro: Paz e Terra, 1977.

NEW YORK FILM ACADEMY. Gender inequality in film. Disponível em: <https://www.nyfa.edu/film-school-blog/gender-inequality-in-film/>. Acesso em: 13 de julho 2018. 